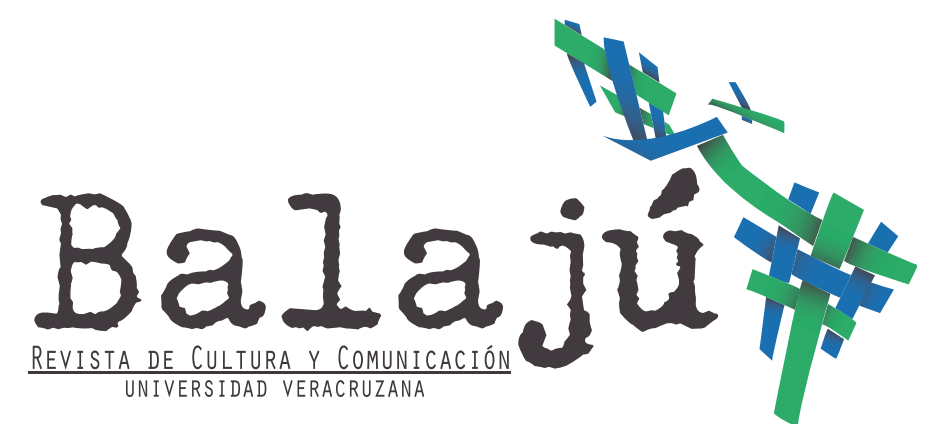

ISSN 2448-4954

No. 1, Año 1

Agosto-Diciembre 2014

\title{
Reseña del libro Lenguajes de la Cotidianidad
}

Daniel Domínguez Cuenca

Universidad Veracruzana, México

*Doctor en Letras por la UNAM. Investigador que labora en USBI-Veracruz, de la Universidad Veracruzana, donde desarrolla el proyecto Reflexionario Mocambo, espacio de producción, investigación y reflexión que explora las fronteras entre la palabra, el acto y la imagen con identidad regional. 


\section{Reseña del libro Lenguajes de la Cotidianidad \\ Por Daniel Domínguez Cuenca}

Gabriela Sánchez Medina y Norma Esther García Meza (coordinadoras), Lenguajes de la cotidianidad, Universidad Michoacana de San Nicolás de Hidalgo/Universidad Veracruzana, México, 2013, 402 pp.

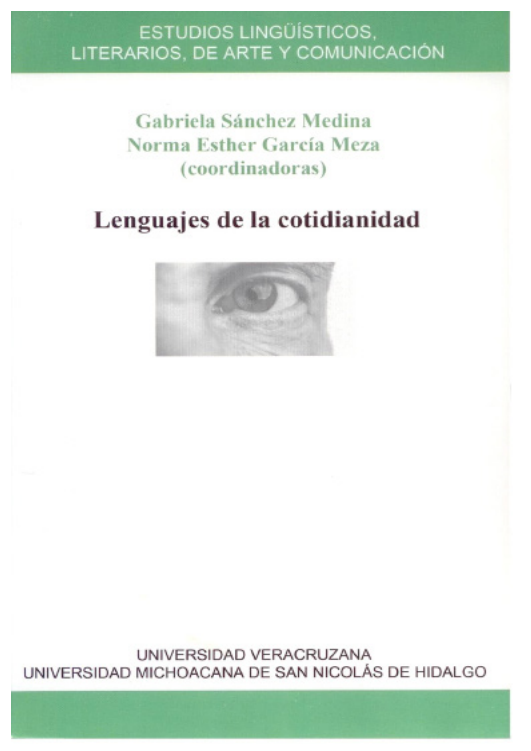

Tengo en mis manos un libro que responde al título: Lenguajes de la cotidianidad, enmarcado con una referencia en fondo verde que advierte: "Estudios lingüísticos, literarios, de arte y comunicación", lo cual da la impresión -al menos así me lo parece- de ser un texto severo. Asunto que podría confirmarse cuando vemos que la publicación comprende trece trabajos diversos de acreditados investigadores bajo el sello editorial de la Universidad Michoacana de San Nicolás de Hidalgo y la Universidad Veracruzana.

Esa es apenas la primera impresión, la fachada rigurosa, limpia y sobria, con la imagen parcial de un rostro que mira e introduce a una serie de ensayos académicos realizados por un grupo de investigadores que viven enclaustrados en sus cubículos. El posible lector podría pensar: de seguro serán textos aburridos escritos en una jerga especializada sólo descifrable por unos cuantos adscritos a esa secta cientificista... Por fortuna, no es así. Este libro es muestra feliz de que la academia y la vida cotidiana no están divorciadas. $\mathrm{Al}$ menos, no necesariamente. Como tampoco está peleado el rigor de estudio con el gusto por la vida y la conciencia social.

Parece un libro de difícil lectura, pero no lo es. Parece un libro para especialistas, sin embargo sus temáticas y tratamientos atañen a todos, 
hombres y mujeres de diversas edades y latitudes, universitarios y académicos tanto como al público en general; a todos aquellos seres interesados en reflexionar sobre el mundo que nos rodea en toda su diversidad, a todos aquellos que estén dispuestos a dar una segunda mirada a las noticias de los diarios, a las canciones que se escuchan en la radio popular, a preguntarse sobre los asuntos de género en primera persona para tomar conciencia y actuar en consecuencia. A todos quienes quieran explorar la lengua nuestra de cada día, la dominante y las marginadas, las otras lenguas, las hablas, los discursos, la memoria, la escritura literaria, la nota roja, la redes sociales, la canción popular, la violencia expresa en la realidad y en la ficción; a reflexionar sobre el imaginario social, la diversidad étnica y las identidades dinámicas; en suma, a cualquiera que interese revisar los muchos y variados lenguajes de la cotidianidad.

Tal vez, para quien quiera leer el libro en el orden establecido, en un inicio, haya que cruzar una aduana con cierta densidad, la aduana teórica. El primer ensayo es un ejercicio que distingue entre lenguaje y discurso, es un puente empedrado por el que no se puede correr, pero al final del cual hay una amplia recompensa para el lector, aquella que le permite ubicar la totalidad de los ensayos desde una perspectiva teórica que avala la pertinencia de los diversos lenguajes de la cotidianidad como materia de estudio. Sin embargo, a pesar de estar situado lógicamente al inicio del libro, nada hay en su estructura que obligue a seguir el orden.

Creo que, sin que se haya propuesto explícitamente, Lenguajes de la cotidianidad es una Rayuela. Se vale empezar en cualquier ensayo y seguir el orden que a cada lector le apetezca, lo que equivale a reconocer que no existe un orden riguroso obligado, que no es necesario leerlo todo y que hay una serie de rutas secretas que conectan a los diversos ensayos entre sí, rutas que cada lector sabrá descubrir.

Mencionaré al azar algunos caminos posibles: "La violencia nuestra de cada día”, texto de Celia del Palacio, actual, incómodo para los que intentan negar o no reconocer este mal que en Veracruz, como en otros estados del país, nos hace andar por la calle con temor, esconder el celular en la vía pública, subirse con miedo al auto en un estacionamiento público y saber, cada día, que alguien (cercano o lejano) está desaparecido, aguzar el oído para distinguir entre un cohete y una detonación de gran calibre en la esquina de tu casa... Esta violencia de hoy, dialoga con otras violencias literarias en el libro, violencias del pasado como sucede con el ensayo de Ariadna Alvarado López. De las representaciones de la violencia registradas en las notas rojas de los diarios de Veracruz en los últimos seis años, podemos saltar a las representaciones de la violencia contenidas en la obra literaria Cartucho. 
La ruta de la violencia, que explora Celia del Palacio en un contexto que acontece cien años más tarde, con base en las secciones de nota roja aparecidas en diversos diarios veracruzanos entre 2006 y 2012, conecta profundamente con las prácticas discriminatorias de género, las que han llevado al silencio y a la marginación a muchas voces femeninas, excluidas de las antologías de la vida. El lector podrá seguir entonces, si lo desea, el sendero que conecta con el periodismo y seguir el ensayo de Josefina Hernández Téllez quien nos comparte los testimonios de dos protagonistas del movimiento feminista de nuestro país, fundamentales para comprender el periodismo de mujeres: Berta Hiriart y Esperanza Brito. Violencia, periodismo, discriminación... en efecto es un libro donde se tocan temas serios y de fundamental importancia. Porque la vida es diversa.

Por otra vía, la mirada y la voz femeninas son exploradas en otro apartado por Elvira Hernández Carballido quien recupera para la memoria las aportaciones de algunas mujeres compositoras en México que durante muchos años estuvieron marginadas, excluidas o acalladas, pero que hoy se hacen sonar por méritos propios alimentando la música nuestra de cada día, en diversos géneros musicales, como el bolero, la balada y el rock.

Sin proponerlo, estamos ya instalados en otra posible ruta del lector por el libro, la que parte desde la música y cuestiona diversos fenómenos de marginación, identidad, valores y resistencia: Antoni Castells i Talens y Yazmín Novelo Montejo realizan un recorrido por la música como vía y expresión de la resistencia cultural y analizan el caso de la canción maya contemporánea en la península de Yucatán.

Desde otra perspectiva, otros nexos entre la música y la narrativa son explorados en las obras Balada y Corrido, de Juan José Arreola, literatura exquisita que explora los cantos de ardidos o mal dolor tanto como la canción popular mexicana representados en el corrido. Así ocurre en el ensayo dedicado a Juan José Arreola, mismo que me ha tocado trabajar en coautoría con Raymundo Acosta Morales.

La ruta musical y la ruta literaria entroncan, pero a su vez dan lugar a nuevas rutas, como es el caso de los ensayos que tienen como eje la memoria. Los textos con evocaciones al pasado conforman otro posible apartado: Norma Esther García Meza, Karina Espinosa Gutiérrez, Édgar García Valencia y Gabriela Sánchez Medina, realizan un recorrido desde la colonia hasta nuestros días para identificar que los arrieros "no lograron desaparecer del todo y, todavía hoy, aparecen en el lenguaje cotidiano cuando incorporamos a nuestro decir alguno de los tantos refranes que hablan de su existencia o cuando dejamos que el bullicio de su trote 
se vuelva a escuchar en las voces que los nombran y los celebran” (p.16). Gabriela Sánchez Medina nos comparte las evocaciones del pasado en el lenguaje cotidiano de un pueblo llamado Cotija de la Paz y nos cuenta su historia de Martín Lutero: "A lo largo de mi vida he escuchado varias veces el relato en voz de mi padre, mi abuela o de algún pariente, y casi siempre se agregan o eliminan detalles a la narración; así que no conozco una versión única o definitiva sino la mezcla de varias en la que se reúnen diversas voces de quienes la recuerdan" (p.17). Y a partir del texto elaborado por Elissa Rashkin, "De la Ciudad letrada al Calibán campesino: la lucha por la tierra y la palabra en el Veracruz posrevolucionario”, podemos partir por las rutas del poder, releer de nuevo con otra mirada la violencia y la marginación, hasta llegar nuevamente a la actualidad: la de las redes sociales y su capacidad de articular movimientos ciudadanos o universitarios como lo señala Alberto Farías Ochoa.

Aparece también otra ruta posible, inversa. La que parte desde el camino del poder o desde el sendero literario, o incluso desde la ruta musical, para internarse en ese horizonte contrario donde la fuerza de la palabra, el valor de lo sonoro, sólo es equiparable al de la pausa, en suma, la ruta del silencio. Así lo propone Ramón Alvarado Ruiz al revisar la obra de Chávez Castañeda en el ensayo titulado "Riaggoé: lenguaje del silencio".

No son todas las rutas, ni son todos los textos, arrieros somos y en el camino andamos, pero toca a cada arriero escoger sus propios senderos e internarse en la exploración que más le llame... Ahora que lo pienso creo que este es un libro que pide como requisito al lector ser curioso, estar dispuesto a explorar una segunda mirada, ser lo suficientemente atrevido como para echar a andar por otro camino posible. 